\title{
PENGARUH TEKNIK SELF TALK TERHADAP KEPERCAYAAN DIRI SISWA KELAS IX SMP NEGERI 9 TARAKAN
}

\author{
Khairina Rasna Indriana, Siti Rahmi \\ Fakultas Keguruan dan Ilmu Pendidikan, Universitas Borneo Tarakan \\ rasnatarakan@gmail.com
}

\begin{abstract}
This study uses a quantitative type with a quasi-experimental approach to nonequivalent control group design. The study population amounted to 244 students, with purposive sampling sampling, the provisions of the study sample obtained 20 students divided into 10 experimental groups and 10 control groups. The instrument used in the form of student confidence scale that has been through validation testing from expert judgment and declared valid. Reliability of the confidence scale was tested using Alpha Cronbach and obtained a coefficient of 0.786 which showed a high level of reliability. Hypothesis analysis using the Wilcoxon test through the SPSS version 24.00 for windows program.

Based on the results of statistical data analysis results of the calculation of the t-test using SPSS version 24.00 for windows obtained a significance value $=0.000<a=0.05$. this shows a significant value of less than 0.05 can be concluded that the hypothesis is accepted, which means that there is an effect of self talk techniques on the confidence of class IX students in Tarakan 9 Middle School Academic Year 2018-1919.
\end{abstract}

Keywords: Self Talk, Student Confidence

\section{PENDAHULUAN}

Ada kesempatan yang sangat baik untuk membantu, menguasai ilmu dan teknologi Remaja merupakan individu yang sesuai dengan tingkat perkembangan berada dalam masa transisi antara masa intelektual, menumbuhkan sikap tanggung kanak-kanak dan memasuki masa dewasa. jawab, menghargai nilai-nilai, dan pada masa ini remaja mengalami mengembangkan sikap percaya diri perubahan emosi, tubuh, minat, pola remaja. (Hurlock, 2010). perilaku, dan kepercayaan diri. Secara Percaya diri merupakan aspek yang psikologis remaja masih labil karena sangat penting untuk mengembangkan belum bisa lepas dari masa anak-anak tapi potensi siswa. Siswa yang memiliki bekal belum bisa dikatakan dewasa. Pada masa percaya diri yang baik, maka siswa dapat mengembangkan potensinya dengan baik, dapat meningkatkan komunikasi dengan

baik, memiliki ketegasan, mempunyai penampilan diri yang baik, dan mampu mengendalikan perasaan. Sebaliknya jika siswa memiliki percaya diri rendah, maka siswa cenderung menutup diri, mudah frustasi ketika menghadapi kesulitan, canggung dalam menghadapi orang disekitar, dan sulit menerima realita dirinya (Ali \& Asrori, 2005). Percaya diri adalah salah satu karakter sifat pribadi yang harus ada pada remaja.

Siswa dengan kepercayaan diri rendah akan menarik diri dari lingkungan dan pergaulan dengan teman. Sebaya Hubungan sosial yang menyenangkan dapat meningkatkan kemauan siswa dalam mengungkapkan suatu pendapat. Kemampuan kepercayaan diri dipengaruhi beberapa faktor yaitu pola asuh, jenis kelamin, pendidikan, interaksi sosial, dan penampilan fisik. Tidak semua siswa memiliki percaya diri yang cukup, siswa yang beranggapan bahwa dirinya tidak mempunyai kemampuan, merasa dirinya tidak berharga, merupakan gambaran individu yang mempunyai masalah kepercayaan diri. Hal ini dapat dilihat dari tingkah laku yang kurang wajar atau menyimpang, seperti rendah diri, terisolir, dan prestasi belajar rendah. 
Menurut Dale (2016) Self talk atau pep-talk adalah cara yang efektif untuk membangkitkan kepercayaan diri dan menciptakan argument berdasarkan buktibukti yang ada, semakin kuat dan semakin jelas bukti tersebut maka akan semakin meyakinkan pesan tersebut. Teknik Self talk berasal dari teori cognitive behavior theraphy, Teori tersebut pada dasarnya meyakini bahwa pola pemikiran manusia terbentuk dari proses rangkaian Stimuluskognisi-respon (SKR), yang saling berkaitan dalam membentuk jaringan di otak manusia

Berdasarkan hasil penelitian Royhan (2016) menunjukkan bahwa rasa percaya diri siswa kelas VIII SMP Wiyata Karya Natar pelajaran 2015/2016 setelah mendapat konseling kelompok dari guru BK, lebih tinggi dibandingkan sebelum mendapat kankoseling kelompok. Ini berarti bahwa rasa percaya diri siswa sudah cenderung menunjukkan dan mengarah pada peningkatan rasa percaya diri siswa. Hal ini berarti bahwa bimbingan kelompok mampu meningkatkan rasa percaya diri siswa serta dapat meningkatkan rasa percaya diri siswa, ini terlihat dari keaktifan peserta dan perubahan perilaku percaya diri siswa setelah diberikan perlakuan konseling kelompok.

Berdasarkan penjelasan tersebut, dapat disimpulkan bahwa percaya diri sangat dibutuhkan siswa dalam belajar, karena akan menunjang keberhasilan siswa dalam menyelesaikan tugas perkembangannya baik dalam proses pembelajaran, lingkungan sosial dan lingkungan keluarga. Namun, kenyataannya masih ada siswa yang mempunyai percaya diri yang rendah, baik itu karena dirinya sendiri maupun dari lingkungannya. Penelitian ini penting dilakukan agar dapat meningkatkan kepercayaan diri sehingga penyesuaian diri siswa baik di lingkungan sekolah ataupun di lingkungan sekitar dapat berjalan dengan lancar. Perbedaan dari peneliti diatas dengan penulis yaitu, subjek yang di teliti oleh Hidayat adalah atlet bulutangkis pemula, sedangkan penulis menggunakan subjek siswa SMP kelas VIII sebagai subjek peneliti. Berdasarkan ciriciri di atas maka penulis mengangkat judul tentang "Pengaruh teknik self talk terhadap kepercayaan diri siswa di SMP 9 Negeri Tarakan".

Berdasarkan pemaparan tersebut, maka penulis tertarik untuk melakukan penelitian dengan judul "Pengaruh teknik self talk terhadap kepercayaan diri siswa kelas IX jurusan Pertanian SMP Negeri 9 Tarakan Tahun Pelajaran 2017/2018”.

\section{METODE PENELITIAN}

Metode penelitian yang digunakan dalam penelitian ini adalah metode eksperimen, yaitu metode penelitian yang digunakan untuk mencari pengaruh perlakuan tertentu terhadap yang lain dalam kondisi yang terkendalikan, dengan memberikan perlakuan lalu diukur akibat dari perlakuan tersebut. Penelitian eksperimen dilakukan untuk membuktikan suatu hipotesis (Sugiyono, 2015).

\section{KESIMPULAN}

Hasil perhitungan uji t-test dengan menggunakan Statistical Product And Service Solution (SPSS) version 24.00 for windows diperoleh nilai signifikansi $=0.000<a=0.05$. hal ini menunjukkan nilai signifikan kurang dari 0,05 dapat ditarik kesimpulan bahwa hipotesis diterima, yang berarti bahwa ada pengaruh teknik self talk terhadap kepercayaan diri siswa kelas IX di SMP Negeri 9 Tarakan Tahun Pelajaran 2018/2019.

Berdasarkan hasil penelitian yang telah dipaparkan peneliti, maka dapat disimpulkan bahwa tingkat kepercayaan diri siswa pada kelompok eksperimen mengalami peningkatan kategori, 8 siswa masuk ke dalam kategori tinggi dengan presentase $80 \%$ dari yang sebelumnya termasuk kategori rendah, 2 siswa masuk ke ketegori sedang dengan presentase $20 \%$ dari yang sebelumnya kategori rendah, namun skor posttest mengalami peningkatan yang signifikan. Namun demikian pada kelompok kontrol tingkat kepercayaan diri siswa yaitu 5 siswa termasuk kategori rendah dengan presentae $50 \%$, dan 5 siswa termasuk kategori sedang dengan presentase $50 \%$.

\section{DAFTAR PUSTAKA}

Arikunto, S. 2013. Prosedur Penelitian: Suatu Pendekatan Praktik. Jakarta: Rineka Cipta.

Ali, M. Asrori, M. 2005. Psikologi Remaja. Jakarta, Bumi aksara.

Aristiani, Rina. 2016. Meningkatkan Kepercayaan Diri Siswa Melalui Layanan Informasi Melalui 
Audiovisual. Journal Konseling Gusjigang, 2 (2): 2460-1187.

Dale, Associates. 2016. Tuntunan Untuk Hidup Lebih Bermakna. Jakarta: PT. Gramedia.

Dita Iswari \& Nurul Hartini. 2005. Pengaruh Pelatihan dan Evaluasi Self-Talk terhadap Penurunan Tingkat Body Dissatisfaction. Journal Unair Surabaya 7 (3) : 2310-7945.

Erford, T. Bradley. 2010. 40 Teknik Yang Harus Diketahui Setiap Konselor. Penata Aksasara.

Ghufron Nur, M. Risnawati Rini, S. 2017. Teori-Teori Psikologi. Jakarta: ArRuzz Media.

Hakim, Thursan. 2005. Mengatasi Rasa Tidak Percaya Diri. Jakarta : Puspa Swara

Hidayat, Y. 2014. The Influence of SelfTalk on Learning Achievement and Self Confidence. Published by Canadian Center of Science and Education. 5 (10) : 1911-2017.

Hurllock, Elizabeth B. 2010. Psikologi Perkembangan. Jakarta: Erlangga.

Indryastuti. (2016). Efektivitas Positif Self Talk Terhadap Motivasi Belajar Siswa Kelas IX SMP. 12 (5).

Prayitno. 2012. Seri Panduan Layanan Dan Kegiatan Pendukung Konseling. Padang: Universitas Negeri Padang.

Royhan, H, Masyah. 2016. Penggunaan Konseling Kelompok Dalam Meningkatkan Percaya Diri Peserta Didik Kelas VII SMP Wiyata Karya Kabupaten Lampung Selatan. Journal Bimbingan dan Konseling, 3 (2) 317 330.

Sugiyono, 2015. Metode Penelitian Pendidikan. Bandung: Alfabeta.

Sriyono, Heru. 2017. Efektifitas Layanan Bimbingan Konseling Di Sekolah Untuk Meningkatkan Kepercayaan Diri Siswa. Research and Development Journal Of Education, 4 (1) : 2406 9744.

Seto, M. 2011. Positive Thinking Vs Positive Attitude. Jogjakarta : Daru Wijayanti.

Widjaya, Hendra. 2016. Berani Tampil Beda dan Percaya Diri. Araska Publisher.

Winarsunu, T. 2002. Statistik Dalam Penelitian Psikologi Pendidikan. Malang: UMM Press. 